\title{
Syntactic abilities in Williams Syndrome: How intact is 'intact'?
}

Victoria Joffe $^{1}$ and Spyridoula Varlokosta ${ }^{2}$

${ }^{1}$ Department of Language and Communication Science, City University, UK

${ }^{2}$ Department of Mediterranean Studies, University of the Aegean, Greece

https://doi.org/10.36505/ExLing-2006/01/0033/000033

\begin{abstract}
The present paper investigates the syntactic abilities of a group of individuals with Williams Syndrome to explore the debates surrounding the dissociation between language and cognition as well as possible dissociations within the language module in this population. Experimental linguistic measures that assess interpretation of passives, pronouns and reflexives as well as elicitation and comprehension of wh-questions were employed. Overall results for the WS group reveal little evidence of the reported spared linguistic abilities in this population thus challenging the idea of a relatively intact language system in WS.
\end{abstract}

\section{Background assumptions and aims}

Neuro-developmental disorders like Williams Syndrome (WS) have been shown to present with a non-linear relationship between cognitive and linguistic abilities, showing better performance in language relative to cognition (Bellugi, Wang \& Jernigan 1994, Clahsen \& Almazan 1998). This has been used as evidence for a dissociation between language and cognition. WS has also been used to support the existence of submodular dissociations within the language faculty. It has been reported that individuals with WS perform better on grammatical tasks (passives, negation, interpretation of reflexives and pronouns, conditionals, formation of regular past tense and plurals) compared with tasks involving lexical processing (irregular past tense and plurals) (Bellugi et al. 1994, Clahsen \& Almazan 1998, 2001).

However, the claims about both kinds of modularity evidenced in WS have not gone unchallenged. Whilst many researchers would agree that the linguistic abilities of individuals with WS are in advance of their cognitive skills (Mervis et al. 2004, among others), the claim of relatively intact linguistic processing has been contested by researchers that present evidence for impaired morphosyntactic abilities along with other linguistic and nonlinguistic abilities (Karmiloff-Smith et al. 1997, among others). Also, there is currently a heated debate on whether any intra-linguistic dissociations exist in WS (Thomas et al. 2001).

In an attempt to further explore the debates surrounding WS, Joffe and Varlokosta (under review) report preliminary new results (from a larger on-

ExLing 2006: Proceedings of 1st Tutorial and Research Workshop on Experimental Linguistics, 28-30 August 2006, Athens, Greece 
going study) on the verbal and non-verbal abilities of a group of nine WS individuals, aged 8.8 to 23.5 years, using a range of standardised and nonstandardised measures. These preliminary results reveal little evidence of the reported spared linguistic abilities in WS as well little support for intra-linguistic dissociations. Any superior performance in rule-governed operations found in the WS cohort, was evident in the two control groups, Down Syndrome (DS) and Typically Developing (TD).

In the present paper we extend the report of Joffe \& Varlokosta (under review) by providing preliminary results from a series of experimental measures that aimed to assess complex computational operations (such as movement) in the same group of WS individuals.

\section{Method \\ Participants}

Nine ( 2 female; 7 male) English-speaking individuals with WS, aged 8.8 to 23.5 years (mean age 12.5), with mean performance IQ of 49.7, participated in the study. Their performance was compared to two control groups: a chronological and cognitive age-matched DS group ( 9 [3 females; 6 males], aged 8.8 to 16.11 years, mean age 12.4 , mean performance IQ 49.7 ) and a younger TD group ( 9 [ 3 females; 6 males], aged 3.8 to 7.11 years, mean age 4.3). Further details about the participants can be found in Joffe and Varlokosta (under review).

\section{Materials and procedure}

Syntactic abilities were assessed through experimental tasks that tested: (a) interpretation of passives: the task included six verbs presented twice in four sentence conditions (active transitive, full verbal passive, short progressive passive and ambiguous passive) yielding a total of 48 sentences; (b) interpretation of pronouns and reflexives: the binding task was a picture selection task with 48 sentences comprised of four conditions: name-pronoun, quantifier-pronoun, name-reflexive, quantifier-reflexive; (c) elicitation and comprehension of wh-questions: 16 sentences were tested (4 who-questions with a subject gap, 4 who-questions with an object gap, 4 which-NP-questions with a subject gap and 4 which-NP-questions with an object gap).

Testing was administered over approximately three-four sessions of around 40 minutes in length usually within a 4-week period. 


\section{Results and discussion}

A series of one and two factor Anova's revealed no significant group differences with the WS group performing at the same level across all tasks as the cognitive age-matched group (DS). There is a trend for the WS group to obtain higher scores than the DS group on the binding, wh-elicitation and passive tasks. However, these differences were not found to be significant. No difference is evident on wh-comprehension with both groups scoring similarly. On the whole, WS and TD groups perform at similar levels (see Table $1)$.

Better performance was evident for WS and TD groups on the binding task compared with the other two comprehension tasks (passives and whquestions). There was a significant main effect for group with planned comparisons revealing significantly better performance on wh-comprehension than $w$-elicitation $(\mathrm{F}(1,21)=72.905, \mathrm{p}<.001)$. This finding follows the typical developmental trend of reception preceding expression. With respect to the binding task, the WS and TD group appear to perform better than the DS group. Nonetheless, our WS subjects performed worse than Clahsen \& Almazan's (1998) subjects (mean chronological age 13.1 and mean IQ 53) on a similar task that assessed anaphoric dependencies. Similarly, our WS subjects performed worse than Clahsen \& Almazan's (1998) subjects in the passive task, reflecting the heterogeneity of the disorder.

Table 1. Correct responses in percentages for all tasks.

\begin{tabular}{|l|l|l|l|l|}
\hline Group & Binding & Passives & Wh-elic & Wh-comp \\
\hline WS & 72 & 49 & 17 & 58 \\
\hline DS & 59 & 41 & 10 & 60 \\
\hline TD & 74 & 60 & 21 & 59 \\
\hline
\end{tabular}

Results for the WS group reveal little evidence of the reported spared linguistic abilities in this population thus challenging the idea of a relatively intact language system. However, patterns of performance may indicate some superiority in language for WS over DS, differences which may prove to be significant with an increase in subjects. Further WS data is being collected to explore these trends further. The language functioning of WS does appear to be complex and the debates are far from resolved.

\section{Acknowledgements}

The authors are grateful for the support of the Williams Syndrome Foundation in the UK, to all the WS, DS and TD participants and their families, and to Amy Riddett, who collected most of the data. The study was funded by an ESRC grant to both authors (RES000-22-0656). 


\section{References}

Bellugi, U., Wang. P. and Jernigan, T. 1994. Williams syndrome: an unusual neuropsychological profile. In Broman, S. and Grafman, J. (eds.) 1994, Atypical Cognitive Deficits in Developmental Disorders. Implications for Brain Function, 23-56. Hillsdale NJ, Erlbaum Press.

Clahsen, H. and Almazan, M. 1998. Syntax and morphology in Williams Syndrome. Cognition 68, 167-198.

Clahsen, H. and Almazan, M. 2001. Compounding and inflection in language impairment: evidence from Williams Syndrome (and SLI). Lingua 111, 729-757.

Joffe, V. and Varlokosta, S. under review. Language abilities in Williams Syndrome: exploring comprehension, production and repetition skills. Advances in Speech-Language Pathology.

Karmiloff-Smith, A., Grant, J., Berthoud, I., Davis, M., Howlin, P. and Udwin, O. 1997. Language and Williams Syndrome: how intact is 'intact'? Child Development 68, 274-290.

Mervis, C.B., Robinson, B., Rowe, M., Becerra, A.M. and Klein-Tasman, B.P. 2004. Relations between language and cognition in Williams syndrome. In Bartke, S. and Siegmüller, J. (eds.) 2004, Williams Syndrome Across Languages, 63-92. Amsterdam/Philadelphia, John Benjamins Publishing.

Thomas, M., Grant, J., Barham, Z., Gsodl, M., Laing, E., Lakusta, L., Tyler, L., Grice, S., Paterson, S. and Karmiloff-Smith, A. 2001. Past tense formation in Williams Syndrome. Language and Cognitive Processes 16, 2/3, 143-176. 